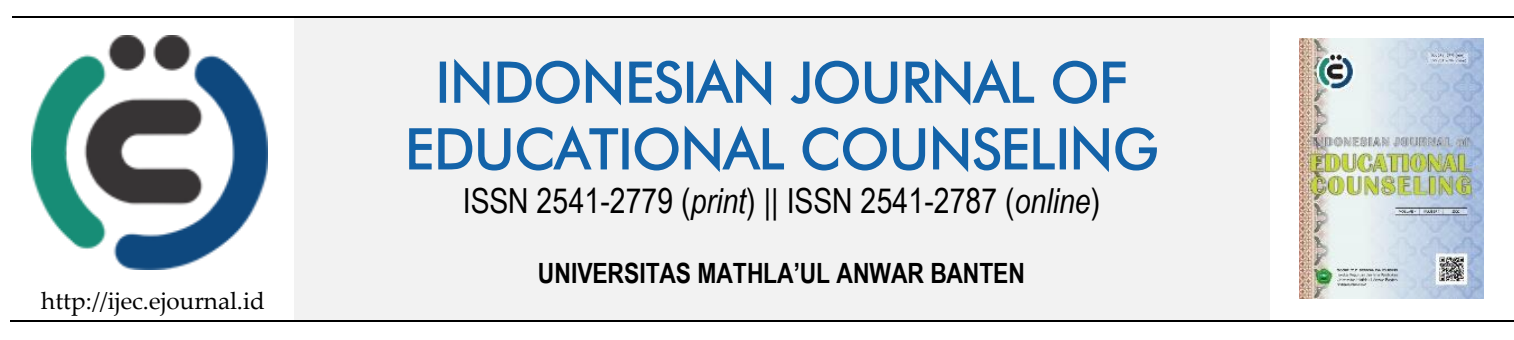

Research Based Article

\title{
Efektivitas Konseling Sebaya untuk Mereduksi Kecanduan Game Online pada Siswa SMP
}

\author{
Rischa Pramudia Trisnani ${ }^{1}$, Silvia Yula Wardani ${ }^{2}$ \\ 1, 2 Universitas PGRI Madiun, Indonesia
}

\begin{tabular}{ll}
\hline Article History & ABSTRACT \\
\hline $\begin{array}{l}\text { Received: 01.10.2019 } \\
\text { Received in revised form: }\end{array}$ & THE EFFECTIVENESS OF PEER COUNSELING TO REDUCE ONLINE GAME \\
14.11.2019 & ADDICTION IN MIDDLE SCHOOL STUDENTS. The ease of using the internet \\
Accepted: 19.12.2019 & is currently widely used by teenagers to operate online games. Online games \\
Available online: 28.01.2020 & are games that can be played together through a network. The high frequency \\
& of online game usage results in teens experiencing online game addiction. \\
& Friends are people outside the family who can provide comfort for teenagers. \\
& Through peer counseling, they hope to be able to exchange ideas and assess \\
& which actions are necessary or not to take. The purpose of this study is to test \\
& the effectiveness of peer counseling to reduce online game addiction in \\
& students. The method used in this research is experimental research. The design \\
& of this study was pre-experimental design. The sampling technique in this \\
& study used porposive sampling where the sample was selected by students who \\
were addicted to online games. Based on the sig (2-tailed) value of 0,000 which & is $<0.05$, it can be concluded that there is a difference between the pretest and \\
posttest scores or effective peer counseling to reduce online game addiction in & \\
& students.
\end{tabular}

KEYWORDS: Cooperative Play, Emotion Regulation, Interpersonal Intelligence.

DOI: $10.30653 / 001.202041 .116$

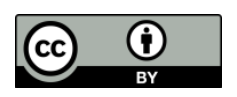

This is an open access article distributed under the terms of the Creative Commons Attribution 4.0 International License, which permits unrestricted use, distribution, and reproduction in any medium, provided the original work is properly cited. ๑) 2020 Rischa Pramudia Trisnani, Silvia Yula Wardani.

\section{PENDAHULUAN}

Teknologi informasi dan komunikasi zaman sekarang mengalami kemajuan yang sangat pesat oleh karena itu remaja harus mampu jeli dalam memilah dan memilih berbagai informasi yang diterima. Adanya internet merupakan salah satu dampak akan majunya teknologi. Berbagai hiburan juga banyak disajikan oleh internet dan bukan hanya kemudahan dalam mendapatkan informasi saja salah satunya adalah game online (Masya \& Candra, 2016). Game Online adalah jenis permainan yang dapat dimainkan oleh banyak orang secara bersama-sama dengan menggunakan suatu jaringan. (Nurlaela \& Ibsik, 2017).

Game online saat ini menjadi primadona dikalangan remaja, khususnya remaja lakilaki menjadi peluang terbesar menjadi pecandu game online. Masa remaja biasanya

${ }^{1}$ Corresponding author's address: Program Studi Bimbingan dan Konseling FIP Universitas PGRI Madiun. Jl. Setiabudi No.85, Kanigoro, Kec. Kartoharjo, Kota Madiun, Jawa Timur 63118, Indonesia. Email: pramudiarischa@ unipma.ac.id 
penasaran dan senang mencoba hal-hal baru, sehingga seringkali kurang menguasai diri jika dibandingkan dengan orang dewasa. Ketika remaja mengoperasikan game online, mereka akan merasakan menjadi pemain yang memperoleh pengalaman yang membahagiakan, mendapatkan sensasi, tantangan, kepuasan, kebebasan dll. Semua kenyamanan yang dirasakan oleh remaja saat mengoperasikan game online sebenarnya akan menimbulkan resiko yang dapat menghancurkan hidup mereka. (Santoso \& Purnomo, 2017).

Remaja yang intensitas bermain game online nya tinggi akan mengakibatkan kecanduan. Individu yang mengalami gejala kecanduan game online akan cenderung lebiih mengutamakan untuk bermain game daripada melakukan pekerjaan lain (Kurniawan, 2017). Seseorang yang bermain game secara berlebihan sehingga dapay menimbulkan pengaruh yang negative terhadap pemain game disebut dengan kecanduan game online (Prastyo, 2017). Remaja yang sudah kecanduan game online tentu saja akan memberikan dampak yang negatif diantaranya yaitu akan malas belajar karena menggunakan banyak waktunya untuk mengoperasikan game online, waktu belajarnya akan digunakan untuk bermain game, ketika orang tua membutuhkan bantuan cenderung tidak peduli, uang yang diberikan untuk jajan dan uang untuk bayar sekolah justru diselewengkan untuk bermain game online, cenderung lupa waktu, pola makan terganggu, menjadi remaja yang emosional serta waktu ibadahpun dilalaikan (Masya \& Candra, 2016).

Berdasarkan Survei Asosiasi Penyelenggaraan Jasa Internet Indonesia (APJII) tahun 2017, sebanyak 143,26 juta orang atau 54,68 persen dari populasi indonesia menggunakan internet. Penetrasi pengguna internet terbesar di usia 13-18 tahun (75,50 persen). Game online adalah perangkat yang paling banyak dipakai untuk mengakses internet $(44,16$ persen). Fakta ini membuktikan bahwa di Indonesia saat ini remaja rawan sekali mudah mengalami kecanduan game online. Sedangkan menurut (Pranitika, Hendriyani, \& Mabruri, 2014) Minat remaja dalam mengoperasikan game online cukup besar, sehingga kebiasaan tersebut dapat memicu terjadinya kecanduan yang dapat merugikan diri sendiri.

Berdasarkan permasalahan kecanduan game online di atas dapat direduksi menggunakan konseling sebaya. Teman sebaya merupakan sosok orang yang penting dalam memberikan warna dalam berbagai aspek perkembangan individu. Hal ini dapat dibuktikan karena banyak remaja yang merasa bahwa orang dewasa tidak dapat memahaminya sehingga keterikatan dan ikatan antar teman sebaya menjadi lebih kuat. Keadaan yang seperti ini membuat remaja menjadi kelompok eksklusif karena menganggap bahwa hanya sesama remajalah yang bisa saling memahami (Prasetiawan, 2016).

Peran remaja merupakan suatu perkumpulan yang nyaman dan strategis yang dapat berperan menjadi pembimbing dan contoh bagi kehidupan remaja (Sarmin, 2017). Interaksi yang dibangun dengan intensif antara remaja akan memberikan pengaruh terhadap berbagai sikap dan tingkah laku baik yang dimunculkan secara positif maupun negative. Konseling sebaya dapat dijadikan sebagai wadah untuk memberikan peluang dan kesempatan bagi konselor sehingga dapat memberikan intervensi bagi remaja untuk melakukan hal yang positif. Suatu bentuk bantuan yang bersifat psikologis dan secara sengaja diberikan dinamakan dengan konseling teman sebaya. Keterampilanketerampilan yang dimiliki oleh siswa dalam memberikan informasi dan pengalaman untuk menumbuhkan kemandirian dan kemampuan mengontrol diri bagi remaja 
merupakan konseling teman sebaya. Konseling sebaya cenderung lebih memfokuskan pada proses yaitu bagaimana berfikir, menggunakan perasaan dan bagaimana mengambil keputusan jadi bukan pada evaluasi. Melalui konseling sebaya apa yang dibutuhkan oleh remaja dapat diberikan sesuai dengan pengalaman yang dimiliki karena yang dibutuhkan adalah respect (Prasetiawan, 2016). Dengan demikian melalui konseling sebaya diharapkan dapat mereduksi kecanduan game online yang dialami oleh siswa.

\section{METODE}

SMP Negeri 2 Wungu merupakan tempat yang digunakan untuk melakukan penelitian ini. Letaknya berada di Desa Mojorayung Kecamatan Wungu, Kabupaten Madiun. Dalam penelitian ini menggunakan pendekatan kuantitatif karena peneliti lebih menekankan fenomena-fenomena yang menggunakan angka-angka dan perhitungan yang pengolahannya menggunakan statistik. Desain penelitian dalam penelitian ini adalah pre eksperiment design, dimana tidak terdapat kelompok kontrol, hanya membandingkan nilai pretest dan posttest saja. Peneliti menggunakan jenis penelitian ini karena membutuhkan yang dapat melihat hasil dengan lebih akurat, yaitu dengan apabila bisa membandingkan keadaan sebelum diberi perlakuan dan sesudah diberi perlakuan (Sugiyono, 2013).

Teknik sampling dalam penelitian ini menggunakan porposive sampling dimana sampel dipilih siswa yang mengalami kecanduan game online. Teknik pengumpulan data dalam penelitian ini menggunakan skala kecanduan game online yang terdiri atas 30 item. Teknik analisis data yang digunakan dalam menganalisis data menggunakan uji beda, yaitu Uji t atau $T$ Test dikerenakan sebaran data dalam penelitian ini normal.

\section{HASIL DAN PEMBAHASAN}

Game online saat ini sedang marak digemari oleh anak-anak maupun remaja. Banyak sekali remaja mengalami kecanduan game online. Berdasarkan hasil pretest yang dilakukan dengan sampel sejumlah 5 anak skor rata-rata kecanduan game online siswa sebesar 85-102 berada pada kriteria tinggi. Secara keseluruhan kecanduan game online siswa sebelum diterapkan layanan konseling sebaya atau peer group counseling berada pada kriteria tinggi.

Tabel 1. Tingkat kecanduan Game online Siswa Sebelum diberikan Konseling Sebaya

\begin{tabular}{llll}
\hline Skor & Kriteria & Jumlah Sampel & Prosentase \\
\hline $30-48$ & Sangat rendah & 0 & 0 \\
\hline $49-66$ & Rendah & 0 & 0 \\
\hline $67-84$ & Sedang & 0 & 0 \\
\hline $85-102$ & Tinggi & 5 & 100 \\
\hline $103-120$ & Sangat tinggi & 0 & 0 \\
\hline Jumlah & & 5 & 100 \\
\hline
\end{tabular}

Tingkat kecanduan game online siswa sebelum diterapkan layanan konseling kelompok atau peer group counseling pada setiap indikator, dimana skor kecanduan game online sebelum diterapkan layanan konseling sebaya atau peer Counseling berada pada kriteria tinggi pada seluruh indikator. Pada indikator cenderung meluangkan waktu untuk bermain game skor rata-rata sebesar 13 dan berada pada kategori tinggi. Sedangkan pada indikator intesitas saat bermain game online skor rata-rata sebesar 15 dan berada 
pada kategori tinggi, pada indikator jenis permainan yang digemari skor rata-rata sebesar 16 dan berada pada kategori tinggi, dan yang terakhir pada indikator kecenderungan menjalimn hubungan dengan orang sekitar skor rata-rata sebesar 15 dan berada pada kategori tinggi.

Tabel 2. Skor Kecanduan Game online Siswa Sebelum diberikan Konseling Sebaya

\begin{tabular}{lllll}
\hline Variabel & Sub Variabel & Indikator & Rerata & Kategori \\
\hline $\begin{array}{l}\text { Kecanduan } \\
\text { Game }\end{array}$ & $\begin{array}{l}\text { Waktu bermain game } \\
\text { Online }\end{array}$ & $\begin{array}{l}\text { Cenderung meluangkan waktu } \\
\text { untuk bermain game }\end{array}$ & 13 & Tinggi \\
\cline { 2 - 5 } & $\begin{array}{l}\text { Frekuensi bermain } \\
\text { game online }\end{array}$ & Intensitas saat bermain game & 15 & Tinggi \\
\cline { 2 - 5 } & $\begin{array}{l}\text { Permainan yang } \\
\text { digemari }\end{array}$ & $\begin{array}{l}\text { Jenis permainan yang sangat } \\
\text { digemari }\end{array}$ & 16 & Tinggi \\
\cline { 2 - 5 } & $\begin{array}{l}\text { Hubungan dengan } \\
\text { orang sekitar }\end{array}$ & $\begin{array}{l}\text { Kecenderungan dalam menjalin } \\
\text { hubungan dengan orang sekitar }\end{array}$ & 15 & Tinggi \\
& & & 14.75 & Tinggi \\
\hline Rata-rata & & & &
\end{tabular}

Berdasarkan hasil pretest tersebut, peneliti sebagai seorang konselor memiliki tergugah untuk memberikan layanan untuk mereduksi kecanduan game online yang dialamai oleh siswa SMP. Layanan yang sesuai untuk mereduksi kecanduan game online adalah konseling sebaya atau peer counseling.

Layanan konseling sebaya dilakukan sebayak 5 kali, dilaksanakan seminggu sekali. Setelah layanan konseling sebaya dilaksanakan sebayak 5 kali dilakukan posttest dengan hasil pada Tabel 3.

Tabel 3. Tingkat kecanduan Game online Siswa Setelah diberikan konseling sebaya

\begin{tabular}{llll}
\hline Skor & Kriteria & Jumlah Sampel & Prosentase \\
\hline $30-48$ & Sangat rendah & 0 & 0 \\
\hline $49-66$ & Rendah & 1 & 20 \\
\hline $67-84$ & Sedang & 4 & 80 \\
\hline $85-102$ & Tinggi & 0 & 0 \\
\hline $103-120$ & Sangat tinggi & 0 & 0 \\
\hline Jumlah & & 5 & 100 \\
\hline
\end{tabular}

Tabel 4. Skor Kecanduan Game online Siswa Setelah diberikan Konseling Sebaya

\begin{tabular}{lllll}
\hline Variabel & Sub Variabel & Indikator & Rerata & Kategori \\
\hline $\begin{array}{l}\text { Kecanduan } \\
\text { Game Online }\end{array}$ & $\begin{array}{l}\text { Waktu bermain } \\
\text { game online }\end{array}$ & $\begin{array}{l}\text { Cenderung meluangkan } \\
\text { waktu untuk bermain game }\end{array}$ & 11.9 & Rendah \\
\cline { 2 - 5 } & $\begin{array}{l}\text { Frekuensi } \\
\text { bermain game } \\
\text { online }\end{array}$ & $\begin{array}{l}\text { Intensitas saat bermain } \\
\text { game }\end{array}$ & 11.8 & Rendah \\
\cline { 2 - 6 } & $\begin{array}{l}\text { Permainan yang } \\
\text { digemari }\end{array}$ & $\begin{array}{l}\text { Jenis permainan yang sangat } \\
\text { digemari }\end{array}$ & 11.5 & Rendah \\
\cline { 2 - 6 } & $\begin{array}{l}\text { Hubungan } \\
\text { dengan orang } \\
\text { sekitar }\end{array}$ & $\begin{array}{l}\text { Kecenderungan dalam } \\
\text { menjalin hubungan dengan } \\
\text { orang sekitar }\end{array}$ & 12.5 & Rendah \\
\hline Rata-rata & & & 11.9 & Rendah \\
\hline
\end{tabular}


Skor kecanduan game online setelah diberikan konseling sebaya berada pada kategori rendah. Pada indikator cenderung meluangkan waktu untuk bermain game skor rata-rata nya sebesar 11.9 dan berada pada kategori rendah. Sedangkan pada indikator intesitas saat bermain game online skor rata-rata sebesar 11.8 dan berada pada kategori rendah, pada indikator jenis permainan yang digemari skor rata-rata sebesar 11.5 dan berada pada kategori rendah, dan yang terakhir pada indikator kecenderungan menjalin hubungan dengan orang sekitar skor rata-rata sebesar 12.5 dan berada pada kategori rendah. Secara keseluruhan skor kecanduan game online sebesar 11.9 dengan kategori rendah.

Berdasarkan perhitungan hasil analisis menunjukkan terjadinya perubahan pada kondisi awal kecanduan game online pada siswa, hal ini ditandai dengan adanya peningkatan perolehan skor skala kecanduan game online siswa baik pada skor total. Adapun penurunan kecanduan game online siswa antara kondisi awal dan kondisi akhir dapat dilihat pada tabel berikut:

Tabel 5. Perubahan Kecanduan Game Online Siswa antara Pretest dan Post-test

\begin{tabular}{lllllll}
\hline \multirow{2}{*}{ Nama } & Pretest & \multicolumn{3}{c}{ Posttest } & \multicolumn{3}{c}{ Perubahan } \\
\cline { 2 - 7 } & Skor & $\%$ & Skor & $\%$ & Skor & $\%$ \\
\hline 1 & 88 & 73.3 & 75 & 62.5 & 13 & 10.8 \\
\hline 2 & 84 & 70 & 66 & 55 & 22 & 15 \\
\hline 3 & 98 & 81.6 & 71 & 59.2 & 27 & 22.4 \\
\hline 4 & 100 & 83.3 & 75 & 62.5 & 25 & 20.8 \\
\hline 5 & 83 & 69.1 & 69 & 57.5 & 12 & 11.6 \\
\hline$\Sigma$ & 386,6 & 75,5 & 300,8 & 59,3 & 19,8 & 16,12 \\
\hline
\end{tabular}

Berdasarkan Tabel 5, dapat dijelaskan bahwa terjadi penurunan tingkat kecanduan game online siswa antara sebelum diberikan perlakuan dan setelah diberikan konseling sebaya. Rata-rata perubahan yang terjadi adalah sebesar 19,8 atau sekitar 16,1\%, dari data pretest sebesar 386,6 atau $75,5 \%$ menjadi 300,8 atau 59,3\%. Rata-rata setiap aspek tingkat kecanduan game online siswa sebelum diberi konseling sebaya berada pada kategori tinggi, setelah diberikan konseling sebaya terjadi penurunan menjadi sedang dan rendah. Ini berarti bahwa konseling sebaya efektif untuk mereduksi kecanduan game online siswa SMP Negeri 2 Wungu Kecamatan Wungu Kabupaten Madiun.

Untuk menguji keefekifan konseling sebaya untuk mereduksi kecanduan game online pada siswa dapat dilakukan dengan menggunakan statistik parametris, yaitu menggunakan Uji $\mathrm{T}$ atau $T$ test yang mana peneliti menggunakan program SPSS. $T$ test digunakan untuk menguji signifikansi hipotesis komparatif 2 sampel yang berkorelasi bila datanya berbentuk ordinal dan atau berjenjang (Sugiyono, 2013). Hasil perhitungan melalui SPSS menunjukkan bahwa paired samples test menunjukkan nilai sig (2-tailed) sebesar 0.000 yang mana $<0,05$, maka dapat disimpulkan bahwa terdapat perbedaan antara nilai pretest dan posttest atau dapat disimpulkan bahwa konseling sebaya efektif untuk mereduksi kecanduan game online pada siswa SMP Negeri 2 Wungu Kabupaten Madiun. 


\section{SIMPULAN}

Tingkat Kecanduan Game online pada siswa SMP Negeri 2 Wungu tergolong pada kriteria tinggi, untuk itu perlu adanya perlakuan khusus untuk mereduksi kecanduan game online yang mereka alami. Berdasarkan hasil analisis $\mathrm{T}$ Test dapat disimpulkan terdapat hubungan antara hasil pretest dan posttest, selain itu terdapat perbedaan antara hasil pretest dan posttest sehingga dapat disimpulkann bahwa konseling efektif untuk mereduksi kecanduan game online pada siswa SMP Negeri 2 Wungu Kabupaten Madiun.

Dengan adanya penelitian ini diharapkan konselor dapat mendampingi siswa yang mengalami kecanduan game online dengan memberikan ketrampilan bagi konselor sebaya agar mau dan mampu dengan baik melakukan konseling sebaya untuk mereduksi kecanduan game online.

\section{REFERENSI}

Kurniawan, D. E. (2017). Pengaruh intensitas bermain game online terhadap perilaku prokrastinasi akademik pada mahasiswa bimbingan dan konseling Universitas PGRI Yogyakarta. Jurnal Konseling GUSJIGANG, 3(1), 98. https://doi.org/10.24176/jkg.v3i1.1120

Masya, H., \& Candra, D. A. (2016). Faktor-faktor yang mempengaruhi perilaku gangguan kecanduan game online pada peserta didik Kelas X di Madrasah Aliyah Al Furqon Prabumulih tahun pelajaran 2015/2016. KONSELI: Jurnal Bimbingan dan Konseling, 3(2), 103-118. https://doi.org/10.24042/KONS.V3I2.575

Nurlaela., \& Ibsik, S. (2017). Dampak game online terhadap moral anak di Desa Malili Kecamatan Malili Kabupaten Luwu Timur. Jurnal Tomalebbi, 1, 93-104.

Pranitika, M., Hendriyani, R., \& Mabruri, M. I. (2014). Hubungan emotion focused coping dengan game online addcition pada remaja di game centre bagian Semarang Barat dan Selatan. Intuisi: Jurnal Psikologi Ilmiah, 6(1), 24-27.

Prasetiawan, H. (2016). Konseling Teman sebaya (peer counseling) untuk mereduksi kecanduan game online. Counsellia: Jurnal Bimbingan dan Konseling, 6(1), 1-13.

Prastyo, Y. (2017). Pembagian tingkat kecanduan game online menggunakan k-means clustering serta korelasinya terhadap prestasi akademik. Elinvo (Electronics, Informatics, and Vocational Education), 2(2), 138-148.

Santoso, Y. R. D., \& Purnomo, J. T. (2017). Hubungan kecanduan game online Dota 2 terhadap penyesuaian sosial pada remaja. PAX HUMANA, 4(1), 27-44.

Sarmin. (2017). Konselor sebaya: Pemberdayaan teman sebaya dalam sekolah guna menanggulangi pengaruh negatif lingkungan. Briliant: Jurnal Riset dan Konseptual, 2(1), 102-112.

Sugiyono. (2013). Metode penelitian kuantitatif kualitatif dan RED. Bandung: Alfabeta. 